BMJ Open Diabetes Research \& Care

\title{
Trends in diabetes in pregnancy in Sweden 1998-2012
}

\author{
Helena E Fadl, ${ }^{1}$ David Simmons ${ }^{2}$
}

To cite: Fadl HE, Simmons D. Trends in diabetes in pregnancy in Sweden 1998-2012. BMJ Open Diabetes Research and Care 2016;4:e00221. doi:10.1136/ bmjdrc-2016-000221

Received 1 March 2016 Revised 7 June 2016 Accepted 17 June 2016

\section{ABSTRACT}

\section{(1) CrossMark}

${ }^{1}$ Department of Obstetrics and Gynaecology, School of Medical Health and Sciences, Örebro University, Örebro Sweden

${ }^{2}$ School of Medicine, Western Sydney University, Campbelltown, New South Wales, Australia

Correspondence to Dr Helena E Fadl; helena.fadl@regionorebrolan. se
Objective: Diabetes in pregnancy has been shown to increase in parallel with the increasing prevalence of obesity. In this national population-based study, we analyzed the trends for gestational diabetes mellitus (GDM), type 1 diabetes in pregnancy, and type 2 diabetes in pregnancy in Sweden between 1998 and 2012.

Research design and methods: A population-based cohort study using the Swedish national medical birth registry data. The time periods were categorized into 3-year intervals and adjusted for maternal body mass index (BMI), ethnicity, and age in a logistic regression.

Results: Each type of diabetes increased over the studied 15-year period. Type 1 diabetes increased by $33.2 \%$ (22.2-45.3) and type 2 diabetes by $111 \%$ (62.2174.4 ) in the adjusted model. Nordic women had the highest prevalence of type 1 diabetes (0.47\%) compared with other ethnic groups. The increase in GDM and, to a lesser extent, type 2 diabetes was explained by country of birth, BMI, and maternal age. The prevalence of GDM in Nordic women $(0.7-0.8 \%)$ did not increase significantly over the time period.

Conclusions: All types of diabetes in pregnancy increased over the 15-year time period in Sweden. Maternal pre-pregnancy BMI remains the key factor explaining the increase in GDM/type 2 diabetes. How to turn around the growing prevalence of diabetes in pregnancy, with its short-term and long-term health effects on both mother and child, requires populationbased interventions that reduce the likelihood of entering pregnancy with a raised BMI.

Globally, all major forms of diabetes in pregnancy (type 1 , type 2 diabetes, and gestational diabetes $(\mathrm{GDM}))$ are on the increase. ${ }^{1}$ Scandinavia is no exception to this, with an increasing prevalence of GDM. ${ }^{2-4}$ In southern Sweden, ${ }^{2}$ where GDM is diagnosed based on 2 hour plasma glucose of $\geq 10.0 \mathrm{mmol} / \mathrm{L}$, the prevalence of GDM increased from $1.9 \%$ to $2.6 \%$ over 10 years, an observation thought to be due to increased rates of obesity and high-risk ethnicity. Increasing rates of GDM have also been reported in Norway $^{3}{ }^{4}$ and in Denmark using different diagnostic criteria (Norway: fasting plasma glucose $\geq 7.0 \mathrm{mmol} / \mathrm{L}$ and/or 2 hour plasma glucose $\geq 7.8 \mathrm{mmol} / \mathrm{L}$; Denmark: 2 hour capillary blood or venous plasma glucose $\geq 9.0 \mathrm{mmol} / \mathrm{L}$ ). While increases in prevalence reflect background trends in diabetes

\section{Key messages}

- Between 1998 and 2012, the prevalence of all types of diabetes in pregnancy increased in Sweden.

- Type 2 diabetes increased by $111 \%$.

- The increase in gestational diabetes mellitus (GDM) was explained by obesity, ethnicity, and maternal age, and in Nordic women there was no increase in GDM prevalence during the time period.

overall (eg, due to increasing prevalence of obesity), they also result from the complex interplay between migration patterns (eg, due to ethnic differences in diabetes risk) and differences between those with and without diabetes on their likelihood of pregnancy (eg, maternal age at conception).

Sweden is fortunate in having national birth and diabetes registers, allowing insight into national patterns in health and disease ${ }^{5}{ }^{6}$ For example, the increased risk of cardiovascular disease among women with prior GDM was recently shown by merging data set extracts from the medical birth register and national patient registers. ${ }^{7}$ Recently, the increasing risk of GDM was shown in southern Sweden using a local register. ${ }^{2}$ The cause was unexplained but thought to be due to changes in ethnic mix, maternal age, and increasing obesity. ${ }^{2}$ Whether these trends are the same across the country and the extent to which they can be explained by these risk factors however remains uncertain. Moreover, the overall trends in type 1 and type 2 diabetes across the country also remain unknown, reflecting a wider international data gap. 8

We have now been able to study the trends in prevalence of GDM, type 1 diabetes, and type 2 diabetes over the whole of Sweden 1998-2012 (1507 699 births). We have also been able to investigate the extent to which these trends are explained by ethnic mix, maternal age, and body mass, and to assess whether any residual growth in diabetes in pregnancy is occurring beyond these risk factors. 


\section{METHODS}

The study population consisted of all pregnancies between 1998 and 2012 registered in the Swedish Medical Birth Register (MBR) that the National Board of Health and Welfare maintains. This national register contains more than $98 \%$ of all births in Sweden from 1973 onwards. Information on all hospital births is gathered prospectively and includes demographic data, reproductive history, and complications during pregnancy, delivery, and the neonatal period. The MBR was validated in 2002, and the quality of the variables included was regarded as high. ${ }^{9}$

In Sweden, the main screening strategy for GDM during the study period was based on repeated capillary random blood glucose with a plasma glucose $\geq 9.0 \mathrm{mmol} / \mathrm{L}$, in combination with traditional risk factors $(88.7 \%$ of the population use this screening model).$^{10}{ }^{11}$ If a risk factor exists (previous large for gestational age child or birth weight $>4500 \mathrm{~g}$, previous GDM pregnancy, heredity, body mass index (BMI) $>30$ in first trimester), an oral glucose tolerance test (OGTT) was undertaken in gestational weeks 28-32. Random blood glucose is measured 4-6 times during pregnancy, with the first measurement in the first trimester. If an OGTT is undertaken in early pregnancy based on a high random glucose and the OGTT is considered normal, the OGTT is repeated in gestational weeks 28-32. A small number of regions in the country have offered a simplified OGTT to all pregnant women since 1995, but only including a 2 hour blood glucose measurement with no fasting glucose sampling $(11.3 \%$ of the pregnant population). ${ }^{12}$

There are no data on exact changes in local routines between the study years. The register does not contain data on laboratory measures such as blood glucose. Maternal pre-pregnancy BMI was calculated as weight in kilograms divided by height in meters squared. BMI was used as a continuous variable, or categorized according to the WHO classes. ${ }^{13}$ Maternal weight was recorded in light indoor clothes at the first antenatal visit in the first trimester. Height was registered on recall. Maternal age was age at delivery.

Diagnosis of GDM is based on the result of a $75 \mathrm{~g}$ OGTT.

During the study period, the main diagnostic criteria for GDM were fasting capillary whole blood glucose $\geq 6.1 \mathrm{mmol} / \mathrm{L}$ (considered equivalent to plasma glucose $7.0 \mathrm{mmol} / \mathrm{L}$ ) and/or 2 hour blood glucose $\geq 9 \mathrm{mmol} / \mathrm{L}$ (considered equivalent to plasma glucose $10.0 \mathrm{mmol} / \mathrm{L}) .^{11}{ }^{14}$ During $1998-2010$, one region (Stockholm-Örebro) diagnosed only those with 'overt diabetes' as GDM (fasting capillary plasma glucose $\geq 7 \mathrm{mmol} / \mathrm{L}$ or 2 hour plasma glucose $\geq 12.2 \mathrm{mmol} / \mathrm{L}$ ). This region represents $\sim 20-25 \%$ of the pregnant population.

The identification of T1DIP was based on coding from International Classification of Diseases 10th Edition (ICD-10): O240, O240B, O24 ${ }^{\circ} \mathrm{C}, \mathrm{O} 240 \mathrm{D}, \mathrm{O} 240 \mathrm{E}, \mathrm{O} 240 \mathrm{~F}$,
O240X. From 1998 onward, the diagnosis of type 2 diabetes in pregnancy was separated from type 1 diabetes coded as ICD O241; hence, 1998 was chosen as the start date for this analysis. The time period was divided into 3-year groups from 1998 onward. The 3-year periods were considered reasonable, to smooth out the year-to-year variation. The coding of type 2 diabetes, which had been uncommon, may have been suboptimal in the first 1-2 years after 1998, but improved with increasing familiarity. Ethnicity was based on country of birth and on the numbers from each country divided into Nordic (Sweden, Denmark, Finland, Norway and Iceland), South Asia (India, Pakistan, Nepal, Bhutan, Sri Lanka, Bangladesh), North Africa (Algeria, Egypt, Djibouti, Libya, Ethiopia, Eritrea, Morocco, Somalia, Tunisia, Sudan), the Middle East (Iran, Iraq, the United Arab Emirates, Bahrain, Gaza area, Jordan, Israel, Lebanon, Kuwait, Palestine, Oman, Qatar, Saudi Arabia, South Yemen, Syria, West bank, Yemen) and Other (other countries, consisting mainly of European countries).

\section{STATISTICS}

Logistic regression was undertaken using both direct entry and stepwise, with no alteration in the results. The association is described in terms of ORs, with $95 \%$ CIs. ANOVA was used for comparing means. All analyses are two tailed with $\mathrm{p}<0.05$ taken as significant.

All statistical analysis was performed using SPSS statistical software, V.22.

\section{ETHICS}

The study was approved by the Regional Ethical Committee in Uppsala, Sweden (2005/216).

\section{RESULTS}

Between 1998 and 2012, there were 1507699 births including $6812(0.5 \%)$ women with type 1 diabetes, 873 $(0.1 \%)$ with type 2 diabetes and $1528(1.0 \%)$ with GDM. Table 1 shows that over this time period there was an increase in maternal age at birth, maternal BMI at booking and non-Scandinavian nationality and an increasing prevalence of each type of diabetes. The prevalence of GDM and type 2 diabetes during pregnancy was higher in South Asians and all other groups than in Scandinavians, but Scandinavians had the highest prevalence of type 1 diabetes (figure 1A-C) during pregnancy.

The logistic regressions in table 2A-C show different relationships between type of diabetes and the key risk factors. Type 1 diabetes during pregnancy increased over the 15-year time period by 33.2 (22.2 to 45.3$) \%$ after adjusting for maternal age, BMI, and ethnicity. Type 2 diabetes during pregnancy increased by 111.0 (62.2 to 174.4$) \%$ with similar adjustments. However, there was no significant difference in GDM prevalence between 1998 and 2000 and 2010 and 2012 after adjusting for maternal age, BMI, and ethnicity. BMI was more 
Table 1 Characteristics of pregnancies with diabetes in Sweden 1998-2012

\begin{tabular}{|c|c|c|c|c|c|}
\hline $\mathbf{N}$ & $\begin{array}{l}1998-2000 \\
261450\end{array}$ & $\begin{array}{l}2001-2003 \\
283917\end{array}$ & $\begin{array}{l}2004-2006 \\
305703\end{array}$ & $\begin{array}{l}2007-2009 \\
321806\end{array}$ & $\begin{array}{l}2010-2012 \\
334823\end{array}$ \\
\hline Body mass index (BMI) $\left(\mathrm{kg} / \mathrm{m}^{2}\right)^{\star \star \star}$ & $\begin{array}{l}24.28(24.26 \text { to } 24.30) \\
(219405)\end{array}$ & $\begin{array}{l}24.50(24.48 \text { to } 24.51) \\
(245421)\end{array}$ & $\begin{array}{l}24.57(24.56 \text { to } 24.59) \\
(267813)\end{array}$ & $\begin{array}{l}24.61(24.60 \text { to } 24.63) \\
(292927)\end{array}$ & $\begin{array}{l}24.75(24.74 \text { to } 24.77) \\
(314140)\end{array}$ \\
\hline BMI $30-34.9$ kg/m² & $7.2 \%(15705)$ & $7.7 \%(18802)$ & $7.9 \%(21238)$ & $8.3 \%(24251)$ & $9.0 \%(28238)$ \\
\hline $\mathrm{BMI} \geq 35.0 \mathrm{~kg} / \mathrm{m}^{2}$ & $2.5 \%(5475)$ & $3.1 \%(7495)$ & $3.4 \%(9014)$ & $3.5 \%(10385)$ & $3.8 \%(11911)$ \\
\hline Maternal age at birth (years) ${ }^{\star * \star}$ & $\begin{array}{l}29.50(29.48 \text { to } 29.52) \\
(261450)\end{array}$ & $\begin{array}{l}29.92(29.90 \text { to } 29.94) \\
(283917)\end{array}$ & $\begin{array}{l}30.28(30.26 \text { to } 30.30) \\
(305703)\end{array}$ & $\begin{array}{l}30.32(30.30 \text { to } 30.34) \\
(321806)\end{array}$ & $\begin{array}{l}30.32(30.31 \text { to } 30.34) \\
(334823)\end{array}$ \\
\hline Percentage of Nordic origin ${ }^{\star \star \star}$ & $84.2 \%(220262)$ & $83.3 \%(236423)$ & $81.7 \%(249638)$ & $79.3 \%(255138)$ & $76.5 \%(256022)$ \\
\hline Percentage of South Asian & $0.5 \%(1370)$ & $0.6 \%(1690)$ & $0.7 \%(2177)$ & $0.9 \%(2867)$ & $1.0 \%(3358)$ \\
\hline Percentage of North African & $1.8 \%(4794)$ & $1.6 \%(4641)$ & $1.7 \%(5117)$ & $2.2 \%(7035)$ & $3.0 \%(10138)$ \\
\hline Percentage of Middle East & $4.0 \%(10358)$ & $4.1 \% 11706)$ & $4.5 \%(13718)$ & $5.2 \%(16603)$ & $5.8 \%(19306)$ \\
\hline Percentage of Other & $9.4 \%(24666)$ & $10.4 \%(29457)$ & $11.5 \%(35053)$ & $12.5 \%(40163)$ & $13.7 \%(45999)$ \\
\hline Type 1 diabetes $(\%)^{\star \star *}$ & $0.38(1000)$ & $0.44(1236)$ & $0.48(1454)$ & $0.48(1547)$ & $0.47(1575)$ \\
\hline Type 2 diabetes $(\%)^{\star \star *}$ & $0.03(85)$ & $0.04(122)$ & $0.04(127)$ & $0.06(193)$ & $0.10(346)$ \\
\hline 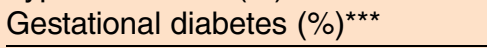 & $0.86(2245)$ & $0.99(2815)$ & $0.92(2820)$ & $1.13(3634)$ & $1.17(3915)$ \\
\hline
\end{tabular}
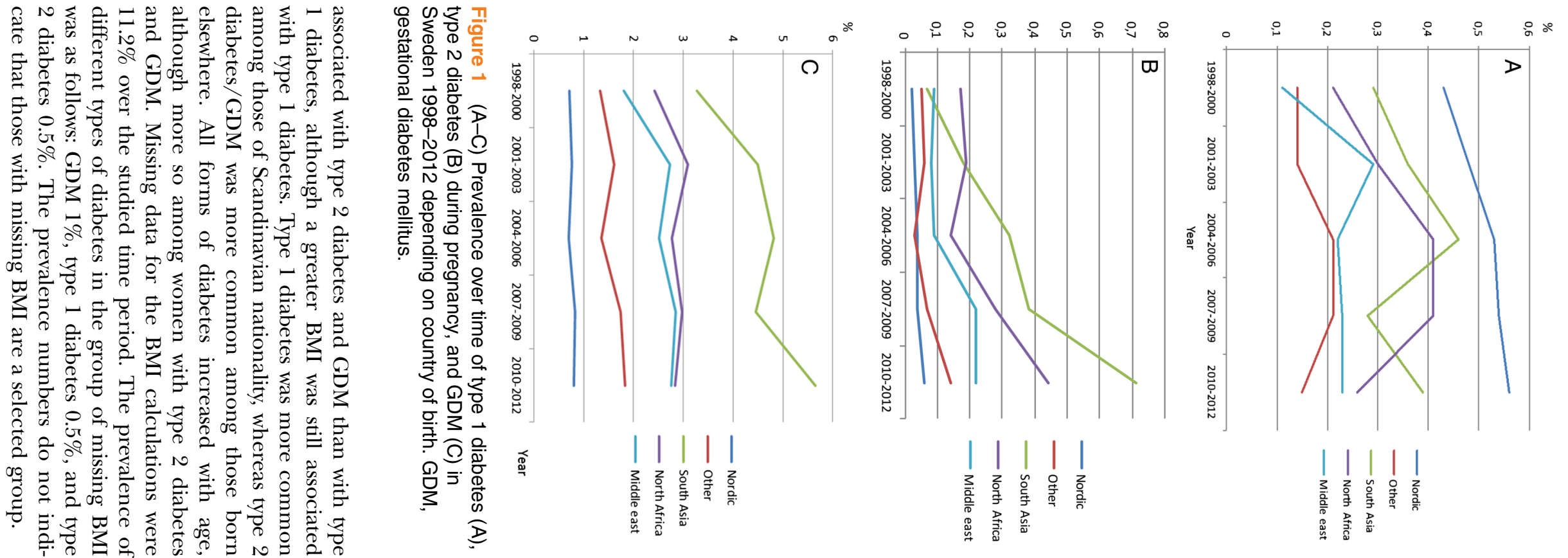
Table 2 Characteristics associated with type 1 diabetes in pregnancy, type 2 diabetes in pregnancy and gestational diabetes in Sweden by logistic regression

\begin{tabular}{|c|c|c|c|}
\hline Variable & OR & $95 \% \mathrm{Cl}$ & Significance \\
\hline \multicolumn{4}{|c|}{ (a) Characteristics associated with type 1 diabetes in pregnancy in Sweden 1998-2012 } \\
\hline Body mass index (per $1 \mathrm{~kg} / \mathrm{m}^{2}$ ) & 1.067 & 1.062 to 1.072 & $<0.001$ \\
\hline Nordic descent (reference) & 1 & & \\
\hline Non-Nordic descent & 0.402 & 0.368 to 0.440 & $<0.001$ \\
\hline Maternal age (per year) & 1.008 & 1.003 to 1.013 & 0.001 \\
\hline $1998-2000$ & 1 & & \\
\hline 2001-2003 & 1.112 & 1.013 to 1.221 & 0.026 \\
\hline 2004-2006 & 1.318 & 1.205 to 1.440 & $<0.001$ \\
\hline 2007-2009 & 1.393 & 1.277 to 1.519 & $<0.001$ \\
\hline 2010-2012 & 1.332 & 1.222 to 1.453 & $<0.001$ \\
\hline Constant & 0.001 & & $<0.001$ \\
\hline \multicolumn{4}{|c|}{ (b) Characteristics associated with type 2 diabetes in pregnancy in Sweden 1998-2012 } \\
\hline Body mass index (per $1 \mathrm{~kg} / \mathrm{m}^{2}$ ) & 1.173 & 1.163 to 1.182 & $<0.001$ \\
\hline Nordic descent (reference) & 1 & & \\
\hline Non-Nordic descent & 2.915 & 2.525 to 3.365 & $<0.001$ \\
\hline Maternal age (per year) & 1.119 & 1.104 to 1.134 & $<0.001$ \\
\hline $1998-2000$ & 1 & & \\
\hline 2001-2003 & 1.064 & 0.779 to 1.454 & 0.696 \\
\hline 2004-2006 & 1.077 & 0.799 to 1.453 & 0.626 \\
\hline 2007-2009 & 1.417 & 1.072 to 1.874 & 0.014 \\
\hline 2010-2012 & 2.110 & 1.622 to 2.744 & $<0.001$ \\
\hline Constant & 0.000 & & $<0.001$ \\
\hline \multicolumn{4}{|c|}{ (c) Characteristics associated with gestational diabetes mellitus in Sweden 1998-2012 } \\
\hline Body mass index (per $1 \mathrm{~kg} / \mathrm{m}^{2}$ ) & 1.138 & 1.135 to 1.141 & $<0.001$ \\
\hline Nordic descent (reference) & 1 & & \\
\hline Non-Nordic descent & 2.816 & 2.719 to 2.917 & $<0.001$ \\
\hline Maternal age (per year) & 1.076 & 1.073 to 1.080 & $<0.001$ \\
\hline 1998-2000 & 1 & & \\
\hline 2001-2003 & 1.064 & 1.001 to 1.132 & 0.048 \\
\hline 2004-2006 & 0.944 & 0.888 to 1.004 & 0.065 \\
\hline 2007-2009 & 1.097 & 1.035 to 1.163 & 0.002 \\
\hline 2010-2012 & 1.038 & 0.980 to 1.099 & 0.208 \\
\hline Constant & 0.000 & & $<0.001$ \\
\hline
\end{tabular}

\section{DISCUSSION}

All forms of diabetes in pregnancy are increasing in Sweden. The increase in GDM, using the variety of screening and diagnostic approaches, ${ }^{11}$ remains completely explicable by increasing maternal age and obesity and the growing number of women born outside of Scandinavia. Conversely, there was a significant growth in type 1 diabetes and type 2 diabetes in pregnancy over this time period even after adjusting for these risk factors. The reasons for such growth are unclear. There is a background increase in type 1 diabetes in Sweden ${ }^{15}$ which remains unexplained. Increasing prevalence of type 2 diabetes is always thought to reflect the growing obesity epidemic, but this does not fully explain the growing rates of type 2 diabetes in pregnancy in Sweden. Women with both type 1 diabetes and type 2 diabetes have been reported to have reduced fertility, ${ }^{16}$ particularly with diabetes complications (eg, nephropathy), and prevalence of diabetes in pregnancy would increase if women with pre-existing diabetes either have less early fetal loss or greater support to conceive (eg, through positive pre-pregnancy counseling, more positive pregnancy experiences). Greater access to in vitro fertilization is unlikely to explain the increase, as access has been similar over the years and is strictly regulated by law in Sweden.

The growth in GDM and its association with increasing obesity remain a major public health threat. ${ }^{1}$ There is now anxiety that these may have effects on the pregnancy itself, as well as cause long-term harm to the offspring. ${ }^{18}$ Of particular concern is that simple interventions during pregnancy, using either lifestyle or metformin, $^{19}{ }^{20}$ do not appear to be sufficient to prevent GDM, nor reduce the risk of macrosomia and other neonatal complications. ${ }^{21}$ With over half of the women in many countries either obese or overweight, there is now a desperate urgency to either prevent overweight/obesity prior to pregnancy, or at least better prepare women for pregnancy. There is some suggestion that pre-pregnancy lifestyle interventions ${ }^{22}$ might meet with more success than antenatal approaches. Until now, recruitment of women into lifestyle interventions in 
early pregnancy (first trimester) has been difficult, but such trials are desperately needed. ${ }^{23}$ The change to the new IADPSG criteria could affect the prevalence of GDM differently in Nordic and non-Nordic populations as found in Norway. ${ }^{24}$ Sweden is soon to adopt the new criteria based on the recommendation of the National Board of Health and changes in GDM prevalence in different populations will be a further subject for research.

\section{STRENGTHS}

The strengths of this study are that the results are based on national data covering almost all pregnancies in Sweden during this study period. The medical birth registry is validated and data are considered good. ${ }^{9}$ The data are prospectively registered in records. We have also had the opportunity to show the prevalence over time for different types of diabetes during pregnancy and taking into account changes in BMI and ethnicity.

\section{WEAKNESSES}

Weaknesses include changes in healthcare that cannot be taken into account in the analyses. For example, maternal healthcare has changed over the past $5-6$ years and now women enter pregnancy care much earlier, with greater focus on the importance of a healthy lifestyle. Even though the diagnostic criteria for GDM have not changed over this time period, screening has changed to some extent with the lowering of the BMI threshold as an indication for OGTT, with some areas identifying more individuals for diagnostic testing. However, we have addressed this to some extent with our adjustment for BMI in our analyses. The criteria for GDM were also different from the latest WHO criteria, ${ }^{25}$ with a higher threshold and no fasting criteria for some centers. Although the prevalence is lower than would be expected with the new criteria, there is no reason to expect the rate of increase in GDM to be any less. Between 1998 and 2010, there were higher diagnostic criteria for GDM in the Stockholm-Örebro region, meaning that GDM prevalence is underestimated in this region during the time period. For the first 1-2 years after 1998, the registration of type 2 diabetes in pregnancy might be incomplete (with some classified as type 1 diabetes in pregnancy), while staff became more familiar with the new coding. Type 2 diabetes in pregnancy and GDM have not been validated in the register; so we cannot rule out that some women have been miscoded.

We have shown that all forms of diabetes in pregnancy are increasing in Sweden. While the increasing prevalence in all cases of GDM, and some cases of type 1 diabetes in pregnancy and type 2 diabetes pregnancy, can be explained by changing patterns in obesity, maternal age, and ethnicity, other factors are involved in this growth. More work is needed to understand the growth in diabetes in pregnancy in type 1 diabetes and type 2 diabetes. Programs such as pre-pregnancy care among women of childbearing age (or before) and to prevent gestational weight gain and maximize healthy eating and physical activity choices could provide one way of improving outcomes. However, more studies are needed regarding different intervention programs and their effects on a population level.

Acknowledgements The authors thank Region Örebro County that funded research time for the investigators.

Contributors HEF and DS conceived the idea and scope for this article, analyzed, wrote the manuscript and revised it before publication. HEF takes full responsibility for the contents of the article.

Funding Region Örebro County, Sweden.

Competing interests None declared.

Ethics approval Uppsala regional ethics committee.

Provenance and peer review Not commissioned; externally peer reviewed.

Data sharing statement No additional data are available.

Open Access This is an Open Access article distributed in accordance with the Creative Commons Attribution Non Commercial (CC BY-NC 4.0) license, which permits others to distribute, remix, adapt, build upon this work noncommercially, and license their derivative works on different terms, provided the original work is properly cited and the use is non-commercial. See: http:// creativecommons.org/licenses/by-nc/4.0/

\section{REFERENCES}

1. Simmons D. Diabetes and obesity in pregnancy. Best Pract Res Clin Obstet Gynaecol 2011;25:25-36.

2. Ignell $\mathrm{C}$, Claesson $\mathrm{R}$, Anderberg $\mathrm{E}$, et al. Trends in the prevalence of gestational diabetes mellitus in southern Sweden, 2003-2012. Acta Obstet Gynecol Scand 2014;93:420-4.

3. Helseth R, Salvesen O, Stafne SN, et al. Gestational diabetes mellitus among Nordic Caucasian women: prevalence and risk factors according to WHO and simplified IADPSG criteria. Scand J Clin Laboratory Invest 2014;74:620-8.

4. Ovesen PG, Jensen DM, Damm P, et al. Maternal and neonatal outcomes in pregnancies complicated by gestational diabetes. A nationwide study. J Matern Fetal Neonatal Med 2015;28:1720-4.

5. Ludvigsson JF, Andersson E, Ekbom A, et al. External review and validation of the Swedish national inpatient register. BMC Public Health 2011;11:450.

6. Ludvigsson JF, Otterblad-Olausson P, Pettersson BU, et al. The Swedish personal identity number: possibilities and pitfalls in healthcare and medical research. Eur J Epidemiol 2009;24:659-67.

7. Fadl $\mathrm{H}$, Magnuson $\mathrm{A}$, Ostlund I, et al. Gestational diabetes mellitus and later cardiovascular disease: a Swedish population based casecontrol study. BJOG 2014;121:1530-6.

8. Jovanovic L, Liang Y, Weng W, et al. Trends in the incidence of diabetes, its clinical sequelae, and associated costs in pregnancy. Diabetes Metab Res Rev 2015;31:707-16.

9. The Swedish medical birth register-a summary of content and quality. National Board of Health and Welfare, 2003. http://www. socialstyrelsen.se/publikationer2003/2003-112-3

10. Ostlund I, Hanson U. Repeated random blood glucose measurements as universal screening test for gestational diabetes mellitus. Acta Obstet Gynecol Scand 2004;83:46-51.

11. Lindqvist $\mathrm{M}$, Persson $\mathrm{M}$, Lindkvist $\mathrm{M}$, et al. No consensus on gestational diabetes mellitus screening regimes in Sweden: pregnancy outcomes in relation to different screening regimes 2011 to 2012, a cross-sectional study. BMC Pregnancy Childbirth 2014; 14:185.

12. Anderberg $\mathrm{E}$, Kallen $\mathrm{K}$, Berntorp $\mathrm{K}$, et al. A simplified oral glucose tolerance test in pregnancy: compliance and results. Acta Obstet Gynecol Scand 2007;86:1432-6.

13. Consultation WHOE. Appropriate body-mass index for Asian populations and its implications for policy and intervention strategies. Lancet 2004;363:157-63.

14. Lind T, Phillips PR. Influence of pregnancy on the 75-g OGTT. A prospective multicenter study. The Diabetic Pregnancy Study Group of the European Association for the Study of Diabetes. Diabetes 1991;40(Suppl 2):8-13.

15. Hussen HI, Persson M, Moradi T. The trends and the risk of type 1 diabetes over the past 40 years: an analysis by birth cohorts and by 
parental migration background in Sweden. BMJ Open 2013;3: e003418.

16. Wiebe JC, Santana A, Medina-Rodriguez N, et al. T1Dgc: Fertility is reduced in women and in men with type 1 diabetes: results from the type 1 diabetes genetics consortium (t1dgc). Diabetologia 2014;57:2501-4.

17. Jonasson JM, Brismar K, Sparen $\mathrm{P}$, et al. Fertility in women with type 1 diabetes: a population-based cohort study in Sweden. Diabetes Care 2007;30:2271-6.

18. Freinkel N. Banting lecture 1980. Of pregnancy and progeny. Diabetes 1980;29:1023-35.

19. Chiswick C, Reynolds RM, Denison F, et al. Effect of metformin on maternal and fetal outcomes in obese pregnant women (EMPOWaR): a randomised, double-blind, placebo-controlled trial. Lancet Diabetes Endocrinol 2015;3:778-86.

20. Simmons D. Prevention of gestational diabetes mellitus: where are we now? Diabetes Obes Metab 2015;17:824-34.
21. Seneviratne SN, Jiang Y, Derraik J, et al. Effects of antenatal exercise in overweight and obese pregnant women on maternal and perinatal outcomes: a randomised controlled trial. BJOG 2015;123:588-97.

22. Tobias DK, Zhang C, van Dam RM, et al. Physical activity before and during pregnancy and risk of gestational diabetes mellitus: a meta-analysis. Diabetes Care 2011;34:223-9.

23. Simmons D, van Poppel MN, Consortium D. Upbeat, Radiel, and Dali: what's the difference? Lancet Diabetes Endocrinol 2015;3:761.

24. Jenum AK, Morkrid K, Sletner L, et al. Impact of ethnicity on gestational diabetes identified with the WHO and the modified international association of diabetes and pregnancy study groups criteria: a population-based cohort study. Eur J Endocrinol 2012;166:317-24

25. WHO. Diagnostic criteria and classification of hyperglycaemia first detected in pregnancy. WHO Publications, 2013. 